\title{
Ectopic Aldosterone Secretion Syndrome
}

National Cancer Institute

\section{Source}

National Cancer Institute. Ectopic Aldosterone Secretion Syndrome. NCI Thesaurus. Code C8442.

A syndrome characterized by abnormal secretion of aldosterone in conjunction with neoplastic growth occurring anywhere in the body. 